severe than they could be. Policing is difficult-even impossible-with mass travel by car and small boats across the Channel. Only education and good sense can prevent irresponsible people from endangering us all. The immediate results of smuggling in a rabies-infected dog might be very similar to those described above, but the efficient measures so rapidly invoked in Vietnam would be put into effect more slowly and with greater difficulty in a civil than a military population.

Veterinary surgeons need to be constantly aware of the possibility that a case of rabies may appear in their surgeries. Doctors, and particularly medical officers of health, would be well advised to keep themselves informed about the disease and make sure they have the rules for post-infection prophylaxis to hand. Enough vaccine and hyperimmune serum should always be available to treat a substantial number of people at short notice. Because of the frequency of reactions after the administration of serum, the need for safe and effective hyperimmune globulin, preferably of human origin, ${ }^{7}$ must be emphasized.

\footnotetext{
1 Moser, R., Aerospace Medicine, 1972, 43, 778.

2 U.S. Public Health Service Advisory Committee on Immunization Practices, Annals of Internal Medicine, 1967, 67, 159.

3 Sellers, T. F., American fournal of Tropical Medicine, 1948, 28, 453.

- Appelbaum, E., Greenberg, M., and Nelson, J., fournal of the American Medical Association, 1953, 151, 188.

Blatt, N. H., and Lepper, M. H., American fournal of Diseases of Children, $1953,86,395$.

- McFadzean, A. J. S., and Choa, G. H., Transactions of the Royal Society of Tropical Medicine and Hygiene, 1953, 47, 372.

7 Ministry of Agriculture, Fisheries and Food, Final Report of the Committe of Inquiry on Rabies, Cmnd. 4696. London, H.M.S.O., 1971.
}

\section{The Quiet Revolution}

The first Cogwheel report ${ }^{1}$ appeared five years ago and led to a quiet revolution in our hospitals, the first major change since the start of the N.H.S. Half the hospital groups in England and Wales have now ${ }^{2}$ started on a "radical revision of traditional methods of organizing medical work in hospitals." But how far have the aims of Cogwheel-more information, better representation, and quicker decisionmaking-really been met? Has translating the report into action interfered at all with clinical freedom? And what changes should still be made to adapt the hospital service to fresh demands from a newly organized Health Service, now only just over 12 months away?

On the whole, as our Special Correspondent has shown in his recent series of articles (the last of which is printed at page 723), Cogwheel has already achieved a lot. More information is now available, decisions are taken sooner than before, and committees now take heed of all the specialties and hospital services. Moreover, compared with the results of the Salmon report ${ }^{3}$ (which was sharply criticized by almost all doctors), Cogwheel has had no adverse effect on the patient. But our Correspondent did encounter some well-founded criticisms. In most cases too little has still been done to get proper representation of some important groups-whether in divisions of their own or as committee members of an already established clinical division. So far both general practitioners and medical officers of health have fared badly, and junior doctors are also often poorly represented on Cogwheel committees-or if they have a place find it difficult to attend. Again, in areas where several hospitals are associated, the geographical gap for the doctor may be bridged by a group executive committee-but the nursing and administrative systems are still largely linked to the individual hospital. The transfer of the hospital social services to the control of the local authority is a prospect which has alarmed many doctors, and in some cases-such as a special hospital serving patients from all over the country ${ }^{4}$-there is a good argument for retaining a team of specialist social workers within the hospital.

All these problems need to be tackled before the N.H.S. reorganization of 1974. Fortunately, from the start the Cogwheel philosophy has always been flexible in principle and practice, aiming to encourage rather than to compel, and there are signs that this flexibility has been retained. Unlike several other working parties, Sir George Godber's group has remained in being, both looking at new aspects of hospital doctors' work and reviewing the effects of its original recommendations. Similar flexibility should characterize the negotiations over the new management structure.

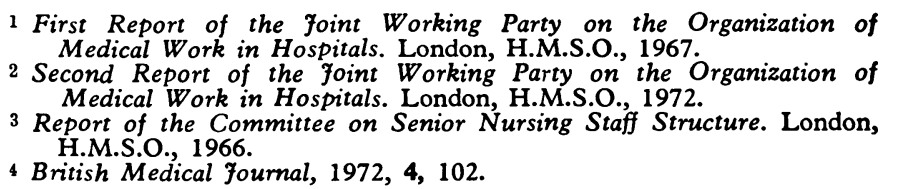

\section{Contraception for the Needy}

Last week's announcement ${ }^{1}$ by the Secretary of State for Social Services that help and advice on family planning are to be expanded within the Health Service has received a cooler welcome than he bargained for. The Department intends to provide more clinics, giving free advice; to expand the domiciliary services; and to encourage the offering of advice and treatment to women after the birth of a baby or an operation for abortion. Some arrangement will be sought by which general practitioners can be paid for their services from public funds instead of by their patients. But, while advice will be free, contraceptive supplies will be free only for people "who have a special social need and who would otherwise be unlikely to undertake effective contraception as well as for those with a financial need." An exception, however, is that women can get supplies free within 12 months of having a baby or an abortion.

Some local authorities are at present offering supplies as well as advice free of charge, so that the new proposals will probably curtail rather than expand their services. But what may prove to be a troublesome question to doctors is how to define social need in this context. When a clearly definable group of people can be identified, such as old-age pensioners or children under 5 , special health provisions are easily made, but with contraception no such convenient groupings are at hand. Amplifying his statement in reply to questions Sir Keith Joseph said the Government would "try to attach the exemption to exemption arrangements already made for other services." But later he also said that it will be necessary "to adhere to the social-medical distinction, and this will be one of the subjects which we shall be discussing with the medical profession."

Experience of the Abortion Act has sufficed to show the difficulties of requiring doctors to make medical decisions on social grounds. Disparities in the interpretation of its requirements are flagrant. They are a source of public annoyance and of professional disquiet, as upsetting to patients as they are damaging to the medical ethos. It is to be hoped that the family planning proposals do not add a further disturbance of this kind.

1 Hansard (House of Commons), 12 December 1972, col. 234. 